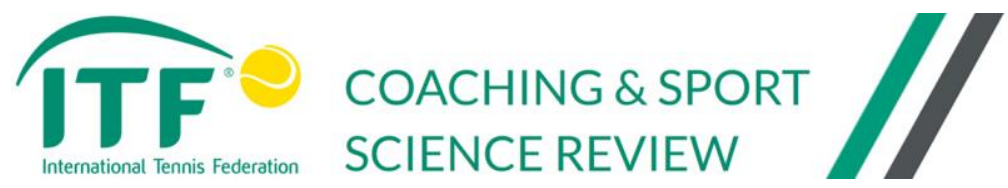 \\ International Tennis Federation \\ www.itfcoachingreview.com \\ August 2020. 28th Year. Issue 81. 16-20 \\ ISSN 2225-4757 \\ https://doi.org/10.52383/itfcoaching.v28i81.34
}

\section{Return to tennis guidelines}

\author{
International Tennis Federation
}

\section{ABSTRACT}

The global COVID-19 outbreak has had a significant impact on tennis. Movement restrictions imposed by governments have resulted in the suspension of the international tennis calendar. Once these restrictions have been relaxed, it may be possible to organise sporting competitions again with or, most likely in the short term at least, without spectators. The primary aim of this document is to set guidelines for minimum and recommended standards for the organisation of tennis competitions. This document has been developed in accordance with the WHO guidelines on the organisation of sports events and with input from the Chair of the ITF Sport Science \& Medicine Commission. It is intended to supplement the existing organisational requirements for ITF events, rather than a substitute for them.
Key words: COVID-19, return, competition.

Received: 1 June 2020

Accepted: 20 June 2020

Corresponding author:

International Tennis Federation, ITF Bank Lane, Roehampton, London SW5XYZ, Great Britain. Email: covid19@itftennis.com

\section{THE ORGANISATION OF TENNIS COMPETITIONS}

\section{General}

Due to the elevated risk posed by COVID-19 to older people and those with underlying health conditions, the ITF does not recommend the organisation of competitions for age groups 60 and above and we advise that any player with a medical condition that may elevate the risk of serious COVID-19 symptoms should be encouraged to avoid participation. The ITF also recognises the threats to integrity associated with a return to tennis, and is working with the Tennis Anti-Doping Programme and the Tennis Integrity Unit to implement appropriate mitigation.

When should competitions not be organised?

If movement restrictions or other national measures that preclude the organisation of competitions have been imposed (or re-imposed) in a country, then these should be followed and no tennis competitions should be organised. These measures take precedence over the guidance in this document.

\section{Organisation competitions}

National Associations should be in regular contact with their respective local, regional or national authorities to establish whether tennis can be organised within the existing movement constraints. Tennis can be played with social distancing measures in place, so it is likely to be one of the first sports for which competitions can be organised. Competitions may not include competitors from other nations until such time as international travel restrictions are lifted.

Minimum and recommended standards
The tables below set out the minimum and recommended standards for the organisation of tennis competitions. These guidelines can only mitigate the risk of COVID-19 infections they cannot eliminate it. Any return to competition and implementation of this guidance should be established in conjunction with the relevant national authorities. 
Table 1. Minimum standards.

\begin{tabular}{|c|c|}
\hline \multicolumn{2}{|c|}{ RECOMMENDED STANDARDS } \\
\hline Actions & Comments \\
\hline 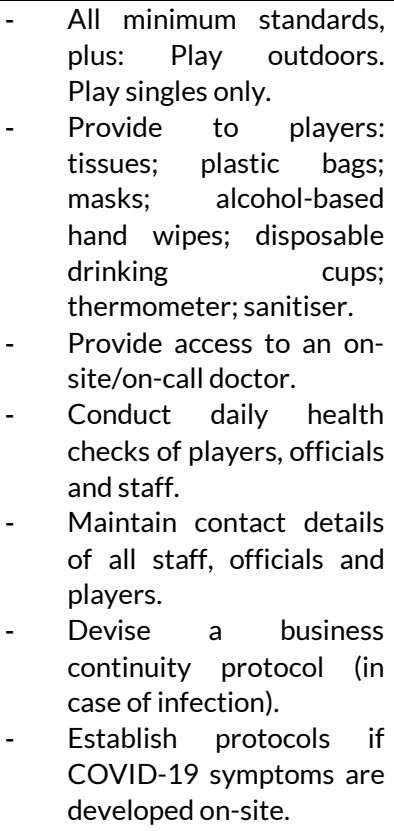 & 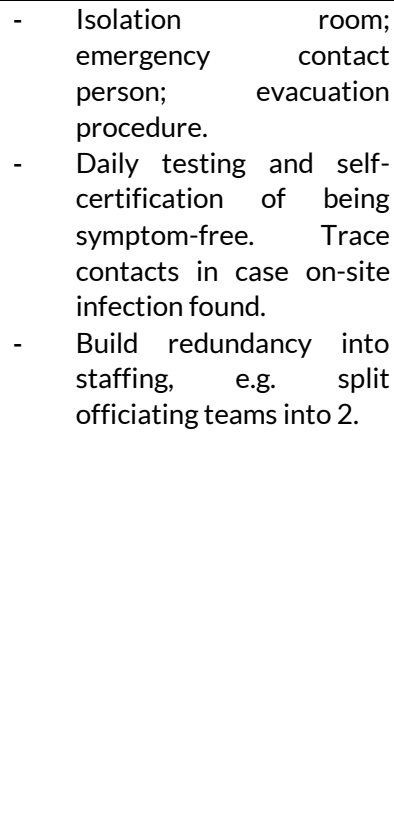 \\
\hline
\end{tabular}

Table 1. Recommended standards.

\section{GUIDANCE FOR NATIONAL ASSOCIATIONS}

In order to facilitate a fast and safe return to tennis, National Associations should maintain a proactive approach to promoting a return to competition. The following suggestions will help to make that return happen as soon as possible.

- Maintain regular contact with local, regional and national authorities (as appropriate and at a personal level if possible) to:

- Ensure that the latest information on movement restrictions, particularly in relation to the organisation of sports competitions is obtained;

- Ensure compliance with all official advice;

- Promote tennis as a sport that can be played with social distancing and should be among the first sports permitted when movement restrictions are relaxed;

- Issue guidance for safe participation to:

- $\quad$ Players;

- Officials;

- Clubs and event organisers;

- $\quad$ Spectators;

- Tournament staff, including medical personnel.

\begin{tabular}{|c|c|}
\hline \multicolumn{2}{|c|}{ MINIMUM STANDARDS } \\
\hline Actions & Comments \\
\hline $\begin{array}{l}\text { - } \quad \text { Implement social distancing: } \\
\text { Modify changeovers. } \\
\text { - } \quad \text { Keep on-court officials and players } \\
\text { separate. } \\
\text { Eliminate handshake and other } \\
\text { - } \quad \text { forms of physical contact. } \\
\text { Implement the ITF Towel policy. } \\
\text { - } \quad \text { Players should arrive at the venue } \\
\text { close to their allotted starting time } \\
\text { and in playing kit and depart } \\
\text { immediately after (no showers). } \\
\text { No sharing of equipment; } \\
\text { Play behind closed doors or with } \\
\text { limited/separated spectators. } \\
\text { Physical separation at locations } \\
\text { where people tend to gather. } \\
\text { Establish hygiene standards: } \\
\text { Daily cleaning and disinfecting of } \\
\text { all shared areas frequently. } \\
\text { Ball kids wear latex gloves on } \\
\text { court. Officials, staff and ball kids } \\
\text { wear masks off- court. } \\
\text { Provide hygiene notices for } \\
\text { players, officials and spectators. }\end{array}$ & 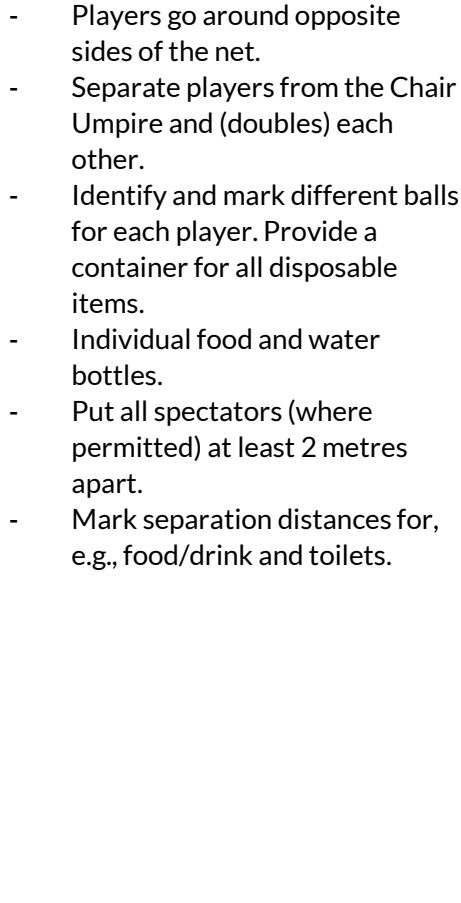 \\
\hline
\end{tabular}

- Display notices clearly around venues, including at entry/exit points, gathering points and around every court.

- Display notices and advice clearly on organisation and tournament websites.

- Advise 'at-risk' groups to not participate or attend venues.

- $\quad$ Advise those with COVID-19 symptoms and those who have come into contact with anyone with COVID-19 symptoms to not attend venues.

- Inform the ITF when movement restrictions are relaxed and tennis can be played, whether at recreational or competition levels.

- Inform the ITF (covid19@itftennis.com) of all national-level events that are organised in your nation.

\section{SAFETY DURING TENNIS COMPETITION PLAYERS AND OFFICIALS}

Pre-competition:

- Reduce injury risk through conditioning prior;

- Consider playing recreationally against members of your household if possible, to reduce the risk of transmission of COVID-19; 
- Do not play if you or members of your household have any COVID-19 symptoms, have been in contact with anyone who has COVID-19 symptoms, are self-isolating or are 'at-risk'.

Implement social distancing during competition at all times, including:

- $\quad$ Arrive at the venue dressed for your match shortly before your allotted start time and depart the venue immediately after the match. Do not use the locker rooms or showers;

- Wear gloves (officials);

- Wear masks while off-court;

- Players and officials should maintain at least 2 metres between each other;

- Do not shake hands with players/opponents or have any other physical/close contact before, during or after a match;

- Each player should use his/her own set of (separately numbered) balls. Balls should be used for one match only;

- Implement the revised ITF 'towel policy';

- At changeovers, go around opposite sides of the net;

- Do not sign autographs or take selfies with fans.

- Do not share any equipment or other items (racket, water bottles, food) with team-mates or opponents;

Observe good hygiene:

- $\quad$ Avoid touching surfaces where possible;

- Wash/sanitise your hands regularly, including before and after bathroom use, and after touching surfaces;

- $\quad$ Cough into a tissue and discard it immediately;

- Don't touch your face.

If you have COVID-19 symptoms within 14 days of a competition, inform the Tournament Director and the ITF at (covid19@itftennis.com).

\section{SAFETY DURING TENNIS COMPETITION SPECTATORS}

Spectators (notices to be posted in prominent locations)
- Ensure that all government restrictions are followed. This may mean limiting the number of spectators or playing 'behind closed doors';

- Require spectators to wear masks in accordance with local guidance or requirements;

- Maintain 2 metres from other spectators in seating areas. If this is impractical, play 'behind closed doors';

- Maintain physical separation when using toilets and purchasing items (separation distances could be marked to encourage compliance);

- Encourage spectators to depart the venue immediately following completion of the match(es) they are interested in.

Observe good hygiene:

- Discourage touching surfaces where possible;

- Encourage washing/sanitising of hands regularly, including pre- and post-bathroom use, and after touching shared surfaces;

- Advise coughing into tissue and discarding them immediately; o Advise not touching their own faces.

In case any spectator experiences COVID-19 symptoms while on-site:

- $\quad$ The Tournament Director must be informed;

- The person must be taken to an isolation room and examined by the Tournament Doctor.

- If the Tournament Doctor suspects COVID-19, then an evacuation procedure should be implemented to ensure the safe transport of the spectator off the site and to the appropriate location;

- $\quad$ Any spectator(s) seated close (within 3 metres) of that spectator should be located and informed of the suspected case and asked to leave the venue and monitor their health;

- Relevant parts of the venue should be disinfected prior to further use.

Advise all spectators who have COVID-19 symptoms within 14 days of attending a tournament to inform the Tournament Director for appropriate follow-up.

Event organisers 
- Assess the risks of organising competitions in your location. Only organise events when permitted by local or national authorities.

- If necessary, play 'behind closed doors' or with limited spectators to comply with restrictions on mass gatherings.

- Do not permit players, officials, staff or spectators who have had COVID-19 symptoms, or who have been in contact with someone who has had COVID19 in the last 14 days to attend the venue.

- $\quad$ Advise 'at-risk' groups to not participate or attend venues;

- $\quad$ Plan for staff absences. Maintain all staff contact details for contact tracing.

- Split officials into two teams, each working separate days (if a member of one team is infected, then the other team works for the remainder of the event).

- Keep office windows open where possible.

- Implement social distancing:

- $\quad$ Organise singles competitions only;

- Mark out separation distances in toilets, at food outlets and other locations where people gather, including tournament offices;

- Ensure players arrive shortly before their matches, dressed to play, and depart immediately afterwards. Do not use locker rooms or showers;

- Separate on-court chairs by 2 metres;

- Separate all spectators by 2 metres where possible;

- Facilitate good hygiene:

- Clean the venue daily; regularly disinfect hightouch surfaces;

- Provide sanitising gel at all entry/exit points;

- Provide all players, officials and staff with masks and latex gloves;

- Provide containers to dispose of contaminated items, tissues and used personal protective equipment. Dispose of these safely.

- Provide medical support:

- Ensure that the on-site doctor has adequate supplies of Personal Protective Equipment, and an infra-red thermometer;

- $\quad$ Provide an isolation room for suspected COVID-19 cases;
- Check the temperature of all players, officials and staff daily; establish a procedure for dealing with on-site COVID-19 cases (isolation location; medical screening; communication flow; transport from site);

- $\quad$ Report all suspected COVID-19 cases to the ITF at (covid19@itftennis.com).

\section{TOURNAMENT STAFF (INCLUDING MEDICAL PERSONNEL)}

- Implement social distancing, including:

- Maintain 2 metres from other staff members at all times (indoors and outdoors).

- Observe good hygiene:

- Wear masks at all times;

- Wash/sanitise your hands regularly, including before and after bathroom use, and after touching surfaces;

- $\quad$ Avoid touching surfaces where possible;

- Disinfect your desk area regularly, including telephone and computer keyboard; o Cough into a tissue and discard it immediately;

- Don't touch your face;

- Do not share any personal items.

- Do not attend the venue if you experience COVID19 symptoms, or if you come into contact with anyone who has symptoms. Inform the Tournament Director and seek medical advice, as appropriate.

- Medical staff:

- Prepare isolation room for suspected COVID-19 cases;

- Maintain adequate supplies of Personal Protective Equipment, and an infra-red thermometer;

- Establish a procedure for dealing with on-site COVID-19 cases, to include isolation, medical screening, communication flow, transport from site;

- $\quad$ Report all suspected COVID-19 cases to the ITF at (covid19@itftennis.com).

\section{QUESTIONS}


If you have any questions about this guidance, please contact the ITF at: covid19@itftennis.com

RECOMMENDED ITF TENNIS ACADEMY CONTENT (CLICK BELOW)

\section{ITF Academy}

